\title{
Influence of Lead Pollution on Cohesive Soil Erodibility using Jet Erosion Tests
}

\author{
Mina M. Salah ${ }^{1} \&$ Abdul-Sahib T. Al-Madhhachi ${ }^{1}$ \\ ${ }^{1}$ Department of Environmental Engineering, College of Engineering, Al-Mustansiriya University, Baghdad, Iraq \\ Correspondence: Abdul-Sahib T. Al-Madhhachi, Assistant Professor, Department of Environmental Engineering, \\ College of Engineering, Al-Mustansiriya University, Baghdad 10047, Iraq; email: abdu@okstate.edu
}

Received: February 15, 2016

Accepted: February 26, 2016 Online Published: February 29, 2016

doi:10.5539/enrr.v6n1p88

URL: http://dx.doi.org/10.5539/enrr.v6n1p88

\begin{abstract}
Recent researches were investigated the high concentrations of Lead in Baghdad soils due to the emissions from Leaded fuel of cars, generators, and the industrials. These high concentrations in addition to their impact on human health may impact on the landscape and streambanks and may cause significant issues on soil erodibility. The erosion rate of cohesive soil was usually estimated using two alternative models, excess shear stress model which is depended on two major soil parameters: the critical shear stress, $\tau_{c}$, and the erodibility coefficient, $k_{d}$, and Wilson model which is depended on two mechanistic soil parameters: $b_{0}$ and $b_{1}$. A new miniature version of Jet Erosion Test ("mini” JET) was performed to derive both model parameters. The objective of this study was to investigate the influence of Lead pollution on cohesive soil erodibility using "mini" JET under controlled laboratory setups to predict soil erodibility. In order to observe the Lead contamination on soil erodibility, soil samples were mixed with different quantities of Lead concertation and the samples were packed at ASTM standard mold on two different bulk densities. Results show that the Lead pollution increased soil erodibility when the concentration of Lead increased. An inverse relationship between excess shear stress parameters $k_{d}$ and $\tau_{c}$ was observed as well as between Wilson model parameters $b_{0}$ and $b_{1}$. The Wilson model parameters were closely resembled the empirical excess shear stress parameters with benefit that Wilson model parameters are mechanistic parameters.
\end{abstract}

Keywords: Lead pollution, soil pollution, erodibility, Jet Erosion Test, sediment detachment

\section{Introduction}

Baghdad City is considered one of the most important and biggest industrialized city in Iraq due to the development and increasing in the population, as a result of increasing in car usages and industrial factories. These increasing in car numbers led to increasing in Lead concentration because the Iraqi oil ministry still adding the tetra alkyl Lead additive as an anti-Knocking agent. For instant, the Lead concentration in Al-Dora region (South of Baghdad, on the banks of the Tigris River) were high (about $846 \mu \mathrm{g} / \mathrm{g}$ ) due to the Lead additives in Al-Dora fuel production plant (Sahib, 2005). As well as to using of Leaded fertilizers in the agricultural lands of Al- Dora region which is located on the Tigris river which is led to the contamination of Tigris riverbanks. Additionally, the Lead contamination of Al-Waziryah region (North east of Baghdad) is up to $25069.6 \mu \mathrm{g} / \mathrm{g}$ due to the presence of Babil car batteries factory (Rahi et al., 2014). This factory used old techniques and had no emission control devices and they had no water treatment plants on the waste water discharges. Therefore, some Baghdad regions are considered very high in Lead contamination risks.

The Lead emissions in the atmosphere is often deposited on the soil surface and correlated with its particulate depending on its characteristics and the conditions of the surrounding media. Lead may be correlated with soil particles into strong chemical bonds and it would be immobile, or Lead may penetrated into the soil through the rainfall and irrigation. When the Lead penetrated into the soil, it would be correlated with the organic compounds, carbonates, and sulfate in the presence of the reaction conditions. All these Lead emissions can be deposited into soil, absorbed by soil, and correlated with the soil in chemical bonds. These bonds may weaken the soil structure and will definitely influence on soil erodibility.

Normally, the soil erodibility is predicted using different models. The excess shear stress model (linear model) is widely used to estimate the erosion rate of cohesive soil based on two empirical parameters: erodibility coefficient, $k_{d}$, and critical shear stress, $\tau_{c}$ (Partheniades, 1965; Hanson, 1990a, 1990b; Al-Madhhachi et al., 
2013a, 2013b; Daly et al., 2015). Additionally, an alternative nonlinear model with more mechanistic parameters was developed (Wilson model). The Wilson model was developed by Wilson (1993a, 1993b) to describe the detachment of single or aggregate soil particles depending on two mechanistic dimensional soil parameters: $b_{0}$ and $b_{1}$. Several studies measure the erodibility of soils using different techniques; Large flumes (Hanson, 1990a; Hanson and Cook, 2004), small flumes (Briaud et al., 2001), laboratory hole erosion test (Wan \& Fell, 2004), and a jet erosion test (Hanson, 1990b; Hanson \& Cook, 2004; Al-Madhhachi et al., 2013a, 2013b, 2014a, 2014b), which is the focused of this study.

There are two versions of JET devices, the original JET (Hanson, 1990b) and the new miniature version of JET referred as "mini" JET (Simon et al., 2010; Al-Madhhachi et al., 2013a, 2013b). The "mini" JET is smaller, lighter, and required less water compared to original JET. It is easy to handle and setup in the field as well as in the laboratory. Al-Madhhachi et al. (2013a) provided equivalent erodibility parameters of "mini" JET with original JET under controlled laboratory setup. Al-Madhhachi et al. (2013b) verified the used of both original and "mini" JETs with flume experiments by deriving both excess shear stress model and Wilson model parameters. Additionally to widely usage of "mini" JET in the laboratory sitting, Daly et al. (2015) used the "mini" JET in the field at the streambanks across the Illinois River watershed in Oklahoma to derive the erodibility parameters and to investigate its variability or uniformity of these parameters at a river basin scale, the relationships between the derived parameters and the soil texture, and the possibility to predict the $k_{d}-\tau_{c}$ relationship.

Several researchers (Hanson, 2001; Wynn and Mostaghimi, 2006; Hanson and Hunt, 2007; Wynn et al., 2008; Regazzoni et al., 2008; Sang et al., 2015) have studied the influence of soil properties on soil erodibility, such as soil texture, soil moisture, bulk density, soil compaction, soil chemical, and vegetation. No studies or researches till now studied the influence of Lead pollution on the soil erodibility. This research is investigated the erodibility in cohesive soil materials that influenced by Lead pollution using "mini" JETs. The objective of this study was to investigate the influence of Lead pollution on soil erodibility using "mini" JET under controlled laboratory setups and comparing the analysis results of excess shear stress model and Wilson model.

\section{Materials and Methods}

\subsection{Analysis Method}

Two alternatives models were presented in this study to derive the erodibility parameters: the linear model (excess shear stress) and nonlinear model (Wilson model). The excess shear stress model is the most commonly used model depends on two empirical parameters $\left(k_{d}\right.$ and $\left.\tau_{c}\right)$ and it is expressed as (Partheniades, 1965; Hanson, 1990a, 1990b):

$$
\mathcal{E}_{r}=k_{d}\left(\tau-\tau_{c}\right)^{a}
$$

where $\mathcal{E}_{r}$ is the detachment rate $(\mathrm{cm} / \mathrm{s}), \tau$ is the average hydraulic boundary shear stress $(\mathrm{Pa})$, and $a$ is an empirical exponent assumed to be unity according to Hanson (1990a, 1990b) and Al-Madhhachi et al. (2013a, 2013b).

Presently, there are three approaches in analyzing data from JETs to estimate the erodibility parameters of the excess shear stress equation. The most popular method of analysis, called Blaisdell's solution (BL), was developed by Hanson and Cook $(1997,2004)$. The solution method was based on principles of fluid diffusion presented by Stein and Nett (1997) and a hyperbolic function modeling the depth progression of the scour hole developed by Blaisdell et al. (1981). The equilibrium depth, $J_{e}$, is defined as the maximum depth of the scour hole beyond which the water jet cannot erode further. This solution method predetermines the $\tau_{c}$ parameter based on $J_{e}$ of scour hole as predicted by the Blaisdell's function as following (Hanson and Cook, 2004):

$$
\tau_{c}=\tau_{o}\left(\frac{J_{p}}{J_{e}}\right)^{2}
$$

where $\tau_{o}=C_{f} \rho_{w} U_{o}^{2}$ is the maximum shear stress due to the jet velocity at the nozzle (Pa); $C_{f}=0.00416$ is the coefficient of friction; $\rho_{w}$ is water density $\left(\mathrm{kg} / \mathrm{m}^{3}\right) ; U_{o}=C \sqrt{2 g h}$ is the velocity of jet at the orifice $(\mathrm{cm} / \mathrm{s}) ; C$ is discharge coefficient (ranged from 0.6 to 0.8 for "mini" JET according to Al-Madhhachi et al., 2013a); $h$ is the pressure head $(\mathrm{cm}) ; J_{p}=C_{d} d_{o}$ is the potential core length from jet origin $(\mathrm{cm}) ; d_{o}$ is the nozzle diameter $(\mathrm{cm})$; and $C_{d}=6.3$ is the diffusion constant. The $k_{d}$ is then determined by solving for the least squared deviation between the observed scour time and predicted time of the following equation (Hanson and Cook, 1997): 


$$
T^{*}-T_{p}{ }^{*}=-J^{*}+0.5 \ln \left(\frac{1+J^{*}}{1-J^{*}}\right)+J_{p}{ }^{*}-0.5 \ln \left(\frac{1+J_{p}{ }^{*}}{1-J_{p}{ }^{*}}\right)
$$

where $T^{*}=t / T_{r}$ is the dimensional time, $t$ is the time of a scour depth measurement, $T_{r}=J_{e} /\left(k_{d} \tau_{c}\right)$ is the reference time according to Stein and Nett (1997), $J^{*}=J / J_{e} ; J$ is the scour depth (cm), and $J_{p}{ }^{*}=J_{p} / J_{e}$.

Alternative solution methods to Blaisdell's solution have been suggested recently (Simon et al., 2010; Daly et al., 2013). One of these solution methods is called scour depth solution (SD). This method simultaneously searches for $k_{d}$ and $\tau_{c}$ which provide the best fit of observed JET data on the scour depth versus time curve predicted by the excess shear stress equation (Eq. 1). The other approach was presented by Simon et al. (2010), and referred to as iterative solution (IT). This method is initialized using the values of erodibility parameters determined by Blaisdell's solution. The scour hole is assumed to reach the equilibrium depth at the end of each test. An upper bound on $\tau_{c}$ is fixed using this equilibrium depth. Then the values of $k_{d}$ and $\tau_{c}$ which minimize the root mean square deviation between the observed scour time and predicted time is searched for iteratively. Finally, the parameters of the excess shear stress model were estimated using these three different solution techniques (BL, SD, and IT) for JET data using Spreadsheet Tool, Version 2.1.1 that developed by Daly et al. (2013).

The general framework for predicting the erosion rate in the Wilson model is based on dislodging and stabilizing forces and associated moment lengths for particle detachment as originally developed by Wilson (1993a, 1993b). The original framework of the Wilson model (Wilson, 1993a, 1993b) was developed for open channel environment. Al-Madhhachi et al. (2013b) incorporated the hydraulics of JET in Wilson model and demonstrated that the parameters of Wilson model can also be determined from the experimental data obtained from the JETs. Al-Madhhachi et al. (2013b) introduced the Wilson model for JET environment as following:

$$
\begin{gathered}
\varepsilon_{r}=b_{0} \sqrt{\tau}\left[1-\exp \left\{-\exp \left(3-\frac{b_{1}}{\tau}\right)\right\}\right] \\
b_{0}=\rho_{s} \frac{k_{r}}{K_{e}} \sqrt{\frac{K_{n}}{k_{d d}\left(\rho_{s}-\rho_{w}\right)}} \\
b_{1}=\left(\frac{\pi}{e_{v} \sqrt{6}}\right) \frac{k_{r}\left(K_{l s}+f_{c}\right)}{K_{o}} g\left(\rho_{s}-\rho_{w}\right) d
\end{gathered}
$$

where $b_{0}$ has dimensions of $\left(\mathrm{M} / \mathrm{L}^{3}\right)^{0.5}$, and $b_{l}$ has dimensions of $\mathrm{F} / \mathrm{L}^{2} ; \rho_{s}$ is particle density; $k_{r}\left(=k_{v} / k_{a}=2 / 3\right)$ is the geometry ratio for a spherical particle; $k_{v}(=\pi / 6)$ is the volume constant of a sphere particle; $k_{a}(=\pi / 4)$ is the area constant of a spherical particle; $K_{e}$ is the exposure of lower particle parameter; $K_{n}$ is a combination of particle and fluid factors; $k_{d d}$ is the detachment distance parameter equal to 2 according to Einstein $(1950)$; $e_{v}$ is the coefficient of variation, equal to 0.35 according to Einstein and El-Samni (1949); $K_{l s}$ is the dimensionless parameter that depends on particle size, its orientation within the bed, and slope; $K_{o}$ is the flow velocity parameter for JET; and $f_{c}$ is the dimensionless parameter based on cohesion.

The parameters $\left(b_{0}\right.$ and $\left.b_{1}\right)$ of the Wilson model were also determined using the spreadsheet tool described by Al-Madhhachi et al. (2013b). The observed particle detachment rate data is fit to equation (4a) by minimizing the sum of squared differences between the observed and modeled scour depth. Hence, the parameters of the model can be determined statistically from observed JET data similar to the linear model.

\subsection{Soil Characteristics and Experimental Procedures}

In this study the soil samples were acquired from Al-Rashdia region, Northern Baghdad. All physical and chemical tests were performed according to ASTM standards as shown in Table (1). Also to investigate the influence of Lead pollution on soil erodibility, a Lead powder (manufactured by the British Drug House, BDH England) was added to the soil samples as micro gram to each gram $(\mu \mathrm{g} / \mathrm{g})$ to obtain the desired concentrations. The "mini" JET device (Figure 1) was used to derive both excess shear stress model and Wilson model parameters. The description, dimension, and functions of this device were defined in Al-Madhhachi et al. (2013a). In this study, the "mini" JET was calibrated according to Al-Madhhachi et al. (2013a) and the coefficient discharge $(C)$ was found to be 0.65 .

The unpolluted soils were air dried and passed through the U.S. Sieve No. 4 (4.75 mm). Then, mixed with different quantities of water to achieve the desired water content, and left for $24 \mathrm{hr}$ in a closed bucket to allow 
for moisture equilibrium. Then, soil moisture content of the samples was determined. Lead powder was added to the dry unpolluted soil and mixed well for 2 to $5 \mathrm{~min}$ to distribute evenly between soil particles. Then, the above procedure was repeated for polluted soil. In order to investigate the influence of Lead pollution on soil erodibility, the soil samples were packed on two different bulk densities. The samples were first prepared by packing the soil in a standard mold ( $101.6 \mathrm{~mm}$ in diameter and $116.4 \mathrm{~mm}$ in height) at standard bulk density (25 blow per layer, three layers for each sample) to achieve standard bulk density of $\left(1.7 \mathrm{Mg} / \mathrm{m}^{3}\right)$ near the optimum water content (17.5) using a manual rammer $(30.5 \mathrm{~cm}$ in height, $50.8 \mathrm{~mm}$ in diameter, and $2.49 \mathrm{~kg}$ in weight) according to ASTM Standard, D698. Other soil samples were packed at uniform bulk density of $1.4 \mathrm{Mg} / \mathrm{m}^{3}$ near the optimum water content of $20 \%$. Then, the top of soil specimen was trimmed and dry density was determined for each soil sample. After that, the soil samples were tested using "mini" JETs by placing the soil specimen in the center of the submergence tank directly below the jet nozzle (Figure 1), adjusting the head tank at the desired constant head ( $63 \mathrm{~cm}$ for all experiments) and connecting the hoses (including water source) to the JET device.

Table 1. Properties of the soils for testing "mini" JET device.

\begin{tabular}{ccccccccccc}
\hline & & \multicolumn{3}{c}{ Soil texture } & \multicolumn{3}{c}{ Standard Compaction } & \\
\cline { 3 - 7 } Site & $\begin{array}{c}\text { USCS } \\
\text { classification }\end{array}$ & $\begin{array}{l}\text { Sand } \\
(\%)\end{array}$ & $\begin{array}{l}\text { Silt } \\
(\%)\end{array}$ & $\begin{array}{l}\text { Clay } \\
(\%)\end{array}$ & $\begin{array}{l}\text { Plasticity } \\
\text { Index }\end{array}$ & $\begin{array}{l}\text { Maximum } \\
\text { Density }\end{array}$ & $\begin{array}{l}\text { Optimum } \\
\text { water } \\
\text { content (\%) }\end{array}$ & $\begin{array}{l}\text { Organic } \\
\text { content } \\
(\%)\end{array}$ & PH \\
\hline $\begin{array}{c}\text { Al-Rashdia, } \\
\text { North } \\
\text { Baghdad }\end{array}$ & Lean Clay & 2.0 & 62 & 36 & 25.5 & 1.7 & 17.5 & 8.8 & 8.7 \\
\hline
\end{tabular}

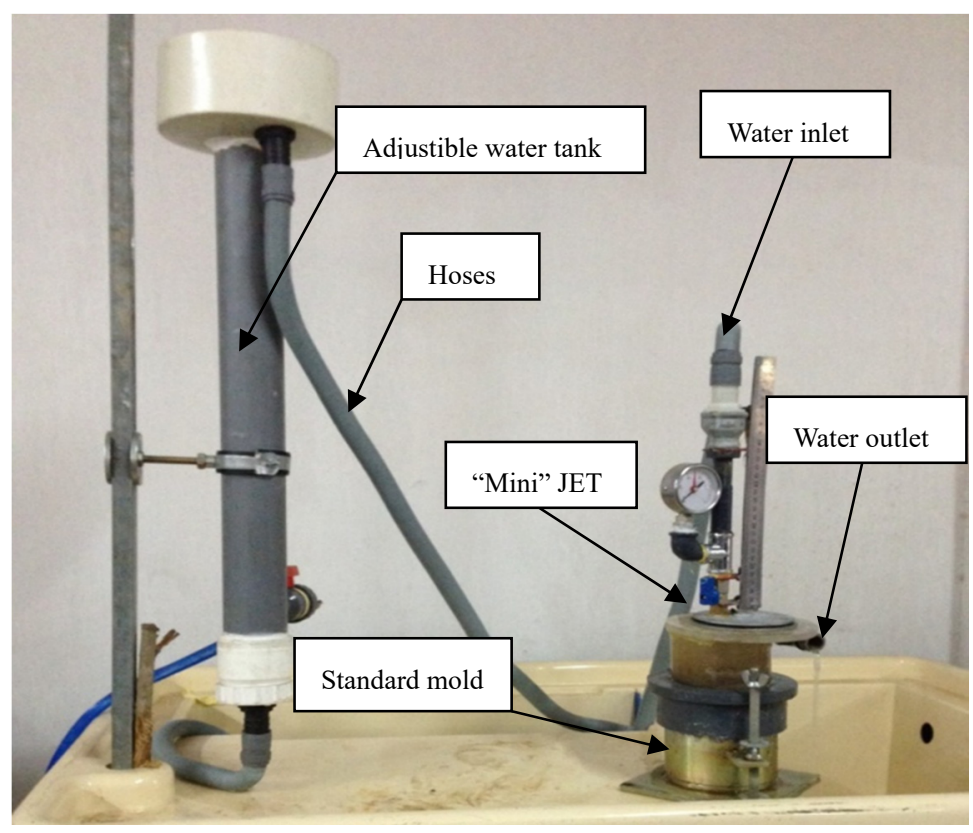

Figure 1. Laboratory setup of the "mini” JET device

Before turning on the water, the height of the jet nozzle was determined by taking the depth gauge readings at the nozzle and the soil specimen surface at time zero. Then, the nozzle was rotated away from impinging on the soil specimen while depth gauge readings were taken. Following depth gauge readings, the water source was opened to fill the head tank. Then, the jet valve was opened to fill the submergence tank. After filling the submergence tank with water, an initial reading of water head was acquired from the top of the adjustable head tank to the water surface at the submergence tank. This reading was held constant during the test. The nozzle was then rotated to impinge directly on the soil specimen surface to start the test and the time was recorded. The readings of the scour bed were taken using the depth gauge at different time intervals. Usually, the first reading was acquired after $30 \mathrm{~s}$ while subsequent readings were acquired each 1 to $10 \mathrm{~min}$ interval with a maximum test 
period of 120 minutes. The tests were repeated twice for each water bulk density. Finally, the "mini" JET data were analyzed to derive erodibility parameters for excess shear stress model and Wilson model as explained previously.

\section{Results and Discussion}

\subsection{Influence of Lead Pollution on the Observed Data}

Lead influenced the observed scour depth measurement of the "mini" JET experiments. Higher erosion rates were observed with higher Lead concentrations. Figure (2) show increasing in erosion rates with increasing the Lead concentration at $1.7 \mathrm{~g} / \mathrm{cm}^{3}$ and $1.4 \mathrm{~g} / \mathrm{cm}^{3}$ bulk densities. There are two reasons for increasing the erodibility due to increasing in the Lead concentration. The first explanation is a physical reason: due to the high density of Lead particles. When increasing the Lead concentration, the mass and the number of Lead particles that penetrate the soil particles increased. The second explanation is a chemical reason. SAAMI (1996) proposed that $\mathrm{Pb}^{0}$ oxidized to $\mathrm{Pb}^{2+}$ and the Lead particles have the ability to the adsorption or ion exchange with the soil particles (Cuber, 2000). The adsorption occurs between cation (Lead particles) and anion (soil particles and organic material).This adsorption correlation weakens the cohesive forces between soil particles. Also, it can be observed that the bulk density had a significant role on the erosion rates, the soil at $1.4 \mathrm{~g} / \mathrm{cm}^{3}$ had less resistance to erosion and more influenced by Lead than $1.7 \mathrm{~g} / \mathrm{cm}^{3}$ bulk density.

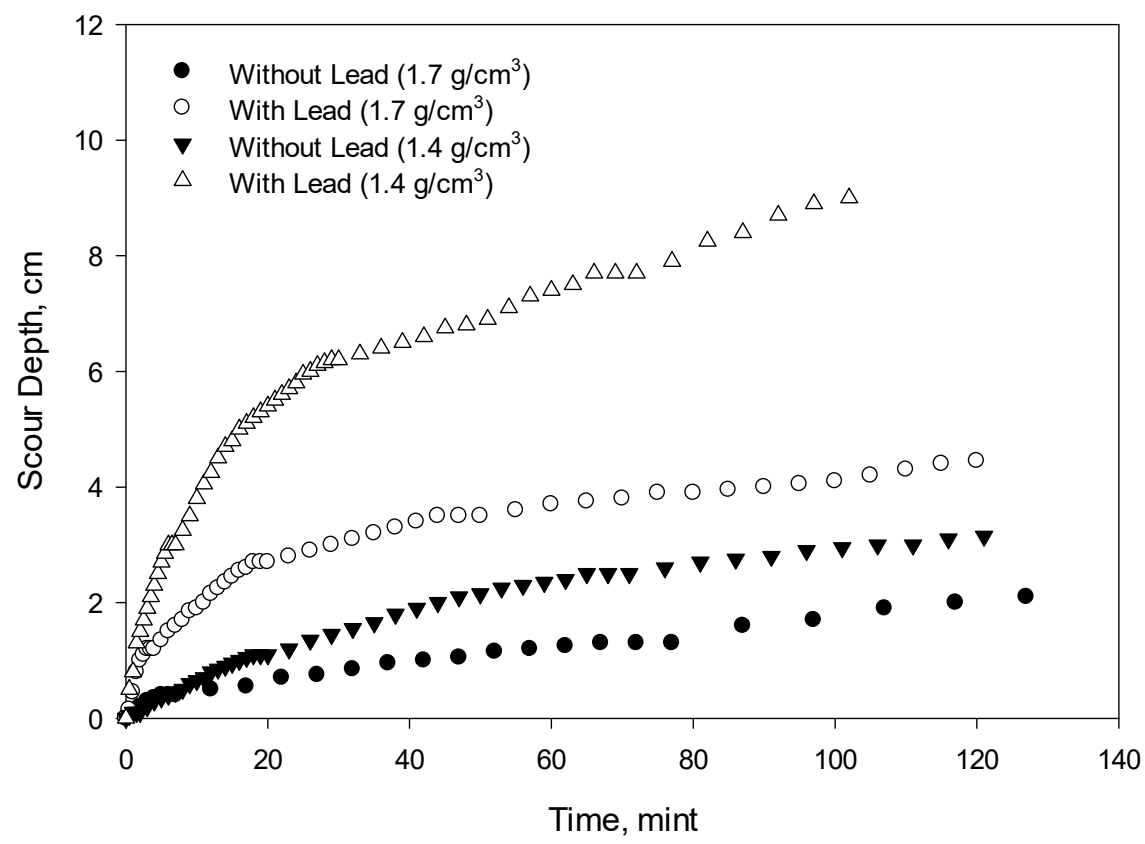

Figure 2. Influence of Lead concertation on the observed scour depth for two different bulk densities: $1.4 \mathrm{~g} / \mathrm{cm}^{3}$ and $1.7 \mathrm{~g} / \mathrm{cm}^{3}$

\subsection{Influence of Lead Pollution on Linear Model}

The excess shear stress parameters $\left(k_{d}\right.$ and $\left.\tau_{c}\right)$ were derived from JET data using three solution techniques: Blaisdell solution (BL), scour depth (SD), and iterative solution (IT). The erodibility coefficient from BL, $k_{d-B L}$, was clearly influenced by Lead pollution as observed in Figure 3a. Even higher $k_{d-B L}$ values were observed with low bulk density $\left(1.4 \mathrm{~g} / \mathrm{cm}^{3}\right)$. From this Figure, it is obvious that the erodibility increased when the Lead concentration increased while the critical shear stress, $\tau_{c-B L}$, was decreased when Lead concertation increased. Similar to BL technique, SD solution of the excess shear stress parameters have the same behavior to BL technique but with different magnitude. The $k_{d-S D}$ increased as Lead concertation increased and the $\tau_{c-S D}$ decreased as Lead concertation increased (Figures $3 \mathrm{c}$ and $3 \mathrm{~d}$ ). In addition, the results of IT solution technique were close to the BL solution technique and the Lead concentrations had the same influence on its parameters (Figures $3 \mathrm{e}$ and 3f). 


\subsection{Influence of Lead Pollution on Non-Linear Model Parameters}

The derived parameters of Wilson model $\left(b_{0}\right.$ and $\left.b_{l}\right)$ at $1.7 \mathrm{~g} / \mathrm{cm}^{3}$ and $1.4 \mathrm{~g} / \mathrm{cm}^{3}$ are shown in Figures $4 \mathrm{a}$ and $4 \mathrm{~b}$. Similar to excess shear stress parameters, the $b_{0}$ increased as Lead concertation decreased while $b_{l}$ decreased. This effect is due to the factors that the mechanistic parameters of $b_{0}$ and $b_{1}$ depend on soil properties and hydraulic parameters. The parameter $b_{0}$ as shown in equation (4b) depends on the soil properties such as particle shape, density, orientation (which influences, $k_{r}$ ) and soil cohesion (which influences, $K_{e}$ ). Therefore, the increasing in $b_{0}$ parameter with increasing the concentration of Lead are due to the facts that $b_{0}$ inversely proportional with the soil cohesion and Lead particles were weaken the bonds between the soil particles (decreasing, $K_{e}$ ). Also, according to equation $(4 \mathrm{c}), b_{1}$ directly proportional with soil cohesion $\left(f_{c}\right)$ so the decreased in $b_{1}$ parameter with increasing in the concentration of Lead are due to this directly proportional and because Lead particles were weaken the bonds between the soil particles (decreasing $f_{c}$ ); therefore, $b_{1}$ decreased. The mechanistic parameters $\left(b_{0}\right.$ and $\left.b_{1}\right)$ explained the physical behavior of empirical parameters of excess shear stress parameters $\left(k_{d}\right.$ and $\left.\tau_{c}\right)$. Previous studies (Al-Madhhachi et al., 2013b, 2014a, 2014b; Daly et al., 2013, 2015) as well as to this study show that the parameter $b_{0}$ has same behavior to $k_{d}$ but with different magnitude and the parameter $b_{1}$ has same behavior to $\tau_{c}$ but with different magnitude.

a) $k_{d}-\mathrm{BL}$
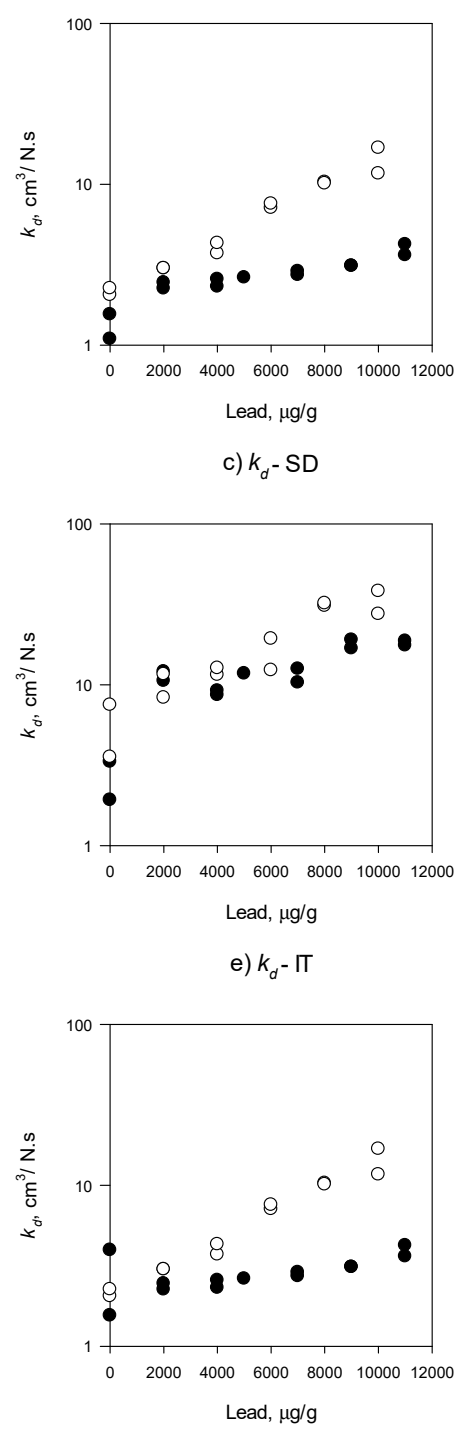

b) $\tau_{c}-\mathrm{BL}$
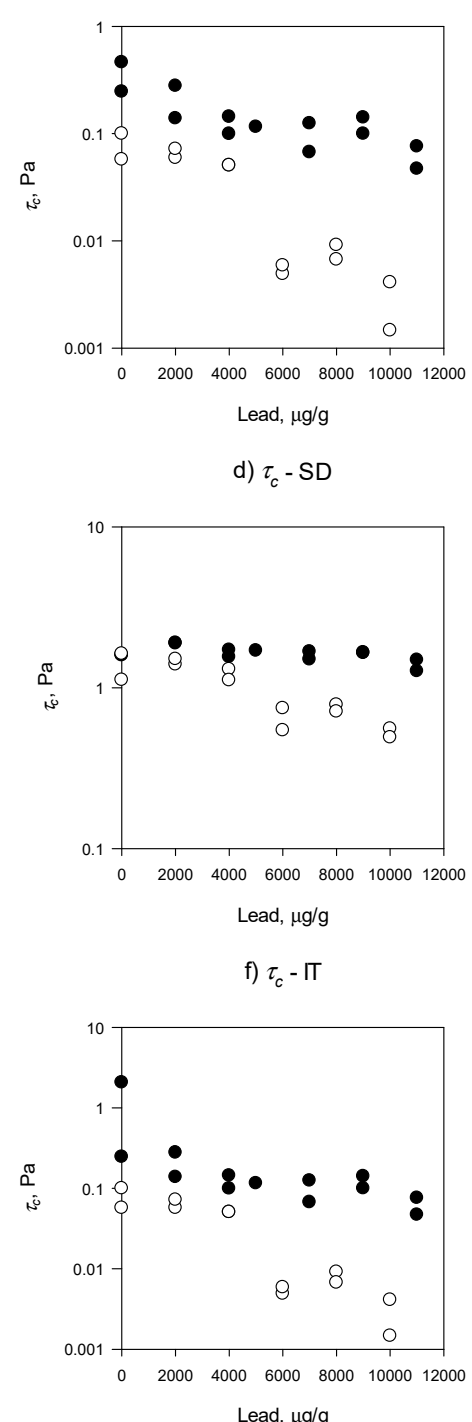

Figure 3. Influence of Lead pollution on excess shear stress parameters for three different techniques: (a) $k_{d}-\mathrm{BL}$, (b) $\tau_{c}-\mathrm{BL},(\mathrm{c}) k_{d}-\mathrm{SD}$, (d) $\tau_{c}-\mathrm{SD}$, (e) $k_{d}-\mathrm{IT}$, and (f) $\tau_{c}-$ IT. Note that sold symbols are for $1.7 \mathrm{~g} / \mathrm{cm}^{3}$ bulk density and empty circle symbols are for $1.4 \mathrm{~g} / \mathrm{cm}^{3}$ bulk density 
a) $b_{0}-\mathrm{WL}$

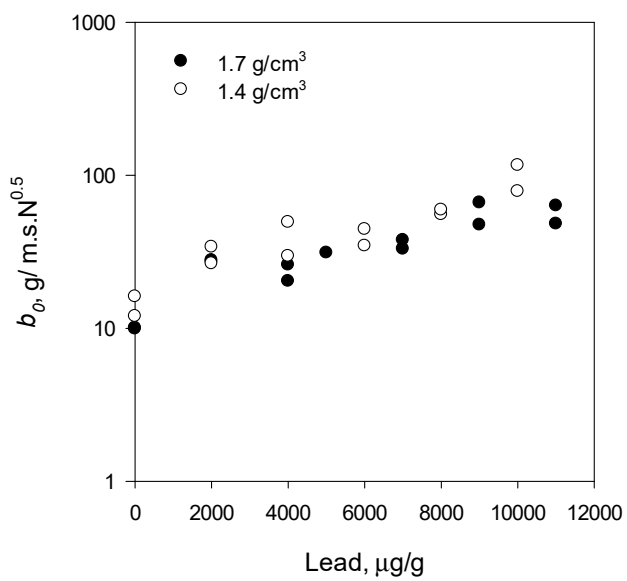

b) $b_{1}-\mathrm{WL}$

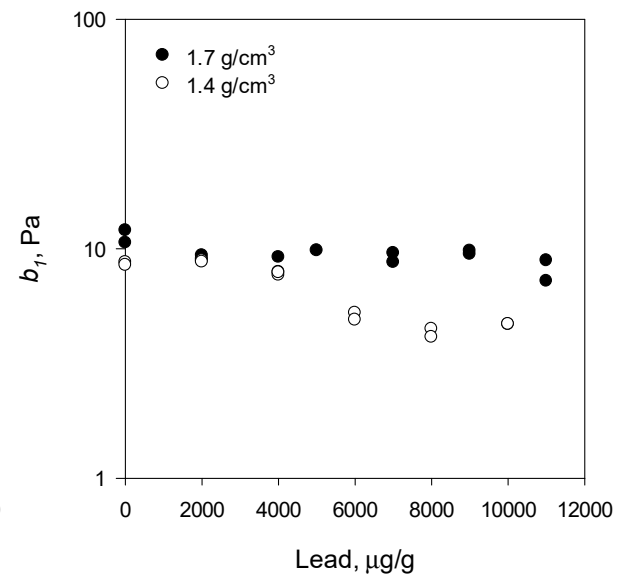

Figure 4. Influence of Lead pollution on Wilson model parameters: (a) $b_{0}-\mathrm{WL}$ and (b) $b_{1}-\mathrm{WL}$. Note that sold symbols are for $1.7 \mathrm{~g} / \mathrm{cm}^{3}$ bulk density and empty circle symbols are for $1.4 \mathrm{~g} / \mathrm{cm}^{3}$ bulk density

\subsection{Linear and Non-Linear Models Comparison}

A Comparison between the models were performed to evaluate those models depending on the relationship of time versus observed scour depth from the "mini" JET experiments and the predicted scour depth from each model versus time at $1.7 \mathrm{~g} / \mathrm{cm}^{3}$ and $1.4 \mathrm{~g} / \mathrm{cm}^{3}$ bulk densities as shown in Figures $5 \mathrm{a}$ and $5 \mathrm{~b}$, respectively. Wilson model (WL) and scour depth solution (SD) technique fitted very close to the observed scour depth data. Blaisdell solution (BL) and Iterative solution (IT) techniques were identical and lower than the observed scour depth. That gave an indication that the performance of SD solution and WL were more consistent than BL and IT solution techniques because the Wilson Model (WL) and SD based on same procedure concept to derive the model parameters that based on minimizing the sum of squared differences between the observed and modeled scour depth data.
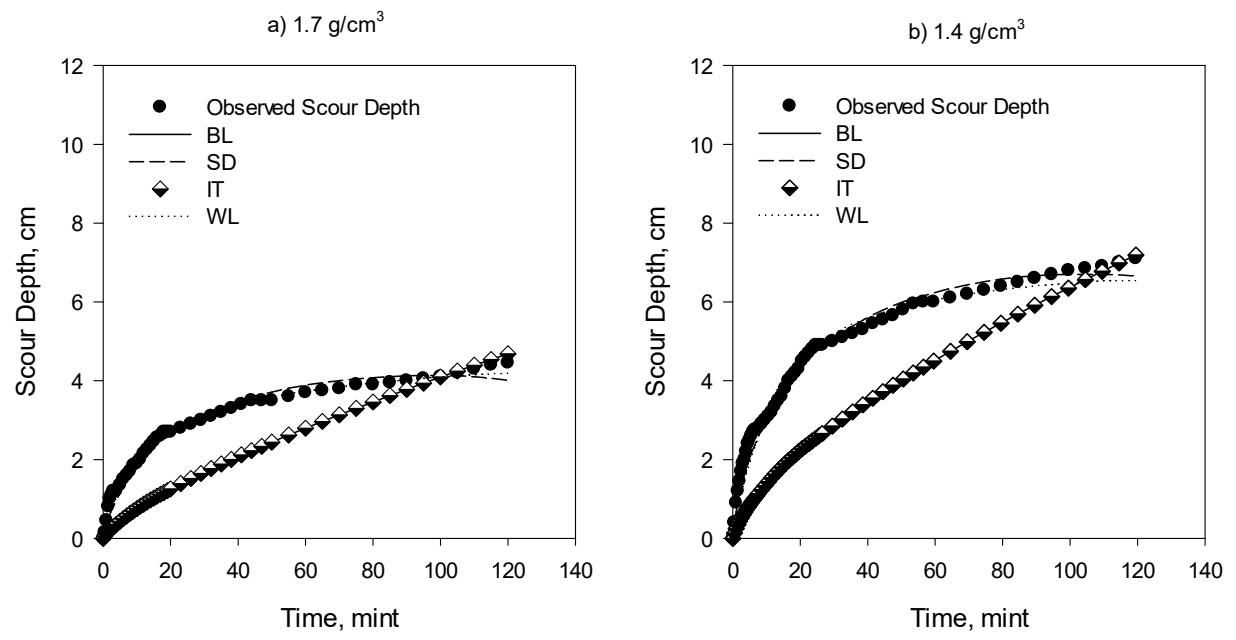

Figure 5. Comparison between the observed and predicted scour depths using excess shear stress model solutions

(BL, SD, and IT) and Wilson model (WL) for two different bulk densities: (a) $1.7 \mathrm{~g} / \mathrm{cm}^{3}$ and (b) $1.4 \mathrm{~g} / \mathrm{cm}^{3}$

From the deriving the model parameters of linear model, an inverse relationship between $\tau_{c}$ and $k_{d}$ was observed from the three techniques: BL, SD, and IT. This inverse relationship for the three linear techniques was compared with the pervious relationships of Hanson and Simon, (2001) and Al-Madhhachi et al., (2013a) (Figure 6). A power law relationship estimated $k_{d}$ as a function of $\tau_{c}$ with an $\mathrm{R}^{2}$ of $0.95,0.50$, and 0.78 for the BL, SD and IT solution techniques, respectively: $k_{d-B L}=1.00 \tau_{c}^{-0.43}, k_{d-S D}=14.44 \tau_{c}^{-0.90}$, and $k_{d-I T}=1.50 \tau_{c}^{-0.32}$. Similar to 
the pervious study of Daly et al. (2015), the relationship between Wilson model parameters $b_{0}$ and $b_{1}$ was observed in a similar fashion of $k_{d}-\tau_{c}$ relationship by an inverse power law relationship as shown in Figure 7 .

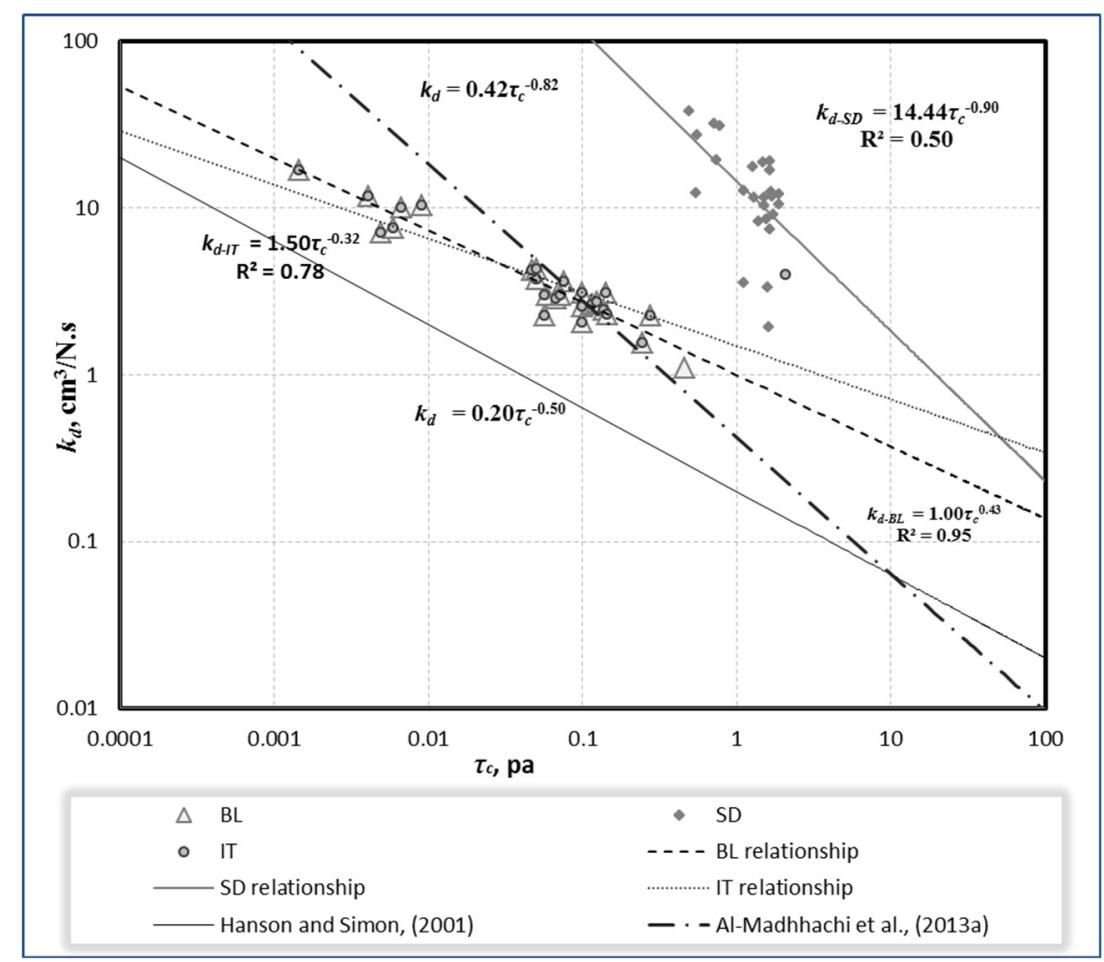

Figure 6. Relationship between $k_{d}$ and $\tau_{c}$ for BL, SD, and IT solutions of excess shear stress model and comparison with previously proposed relationships by Hanson and Simon (2001) and Al-Madhhachi et al.

(2013a)

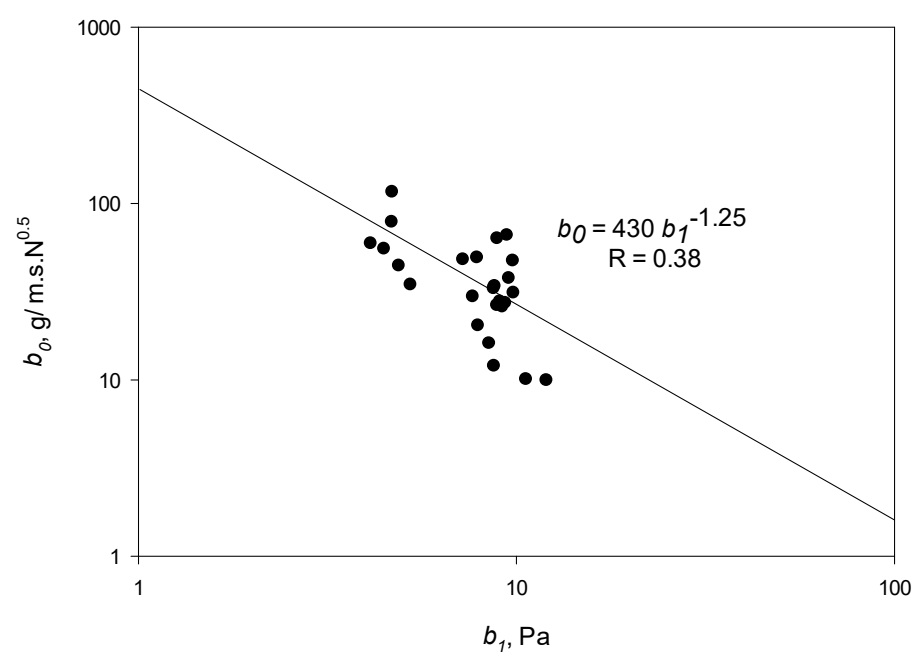

Figure 7. Relationship between Wilson model parameters $b_{0}$ and $b_{1}$

A relationship of $k_{d}$ versus $b_{0}$ and $\tau_{c}$ versus $b_{l}$ for each solution technique were developed in order to investigate the model parameter relationships (Figure 8). When using the parameters derived with BL solution technique, a relationship was observed between $b_{0}$ and $k_{d}$ with $\mathrm{R}^{2}=0.65$ and between $b_{1}$ and $\tau_{c}$ with $\mathrm{R}^{2}=0.89$ as shown in Figures (8a) and (8b), respectively. For parameters derived with SD solution technique, the $b_{0}-k_{d}$ relationship was observed with $\mathrm{R}^{2}=0.87$ and $b_{1}-\tau_{c}$ relationship with $\mathrm{R}^{2}=0.82$, as shown in Figure (8c) and (8d), respectively. For the parameter derived with IT solution technique, the $b_{0}-k_{d}$ relationship was observed with $\mathrm{R}^{2}=0.50$ and $b_{1}-\tau_{c}$ 
relationship with $\mathrm{R}^{2}=0.86$, as shown in Figure (8e) and (8f). Therefore, the mechanistic parameters $b_{0}$ and $b_{1}$ were resembled empirical parameters $k_{d}$ and $\tau_{c}$, for all three solution techniques, but with different magnitudes. Note that the parameters of Wilson model were derived in a similar technique as SD solution technique for the excess shear stress parameters. This is similar to the previous observations by Al-Madhhachi et al. (2013b) and Daley et al. (2015) due to both Wilson model and SD technique based on same solution concept.
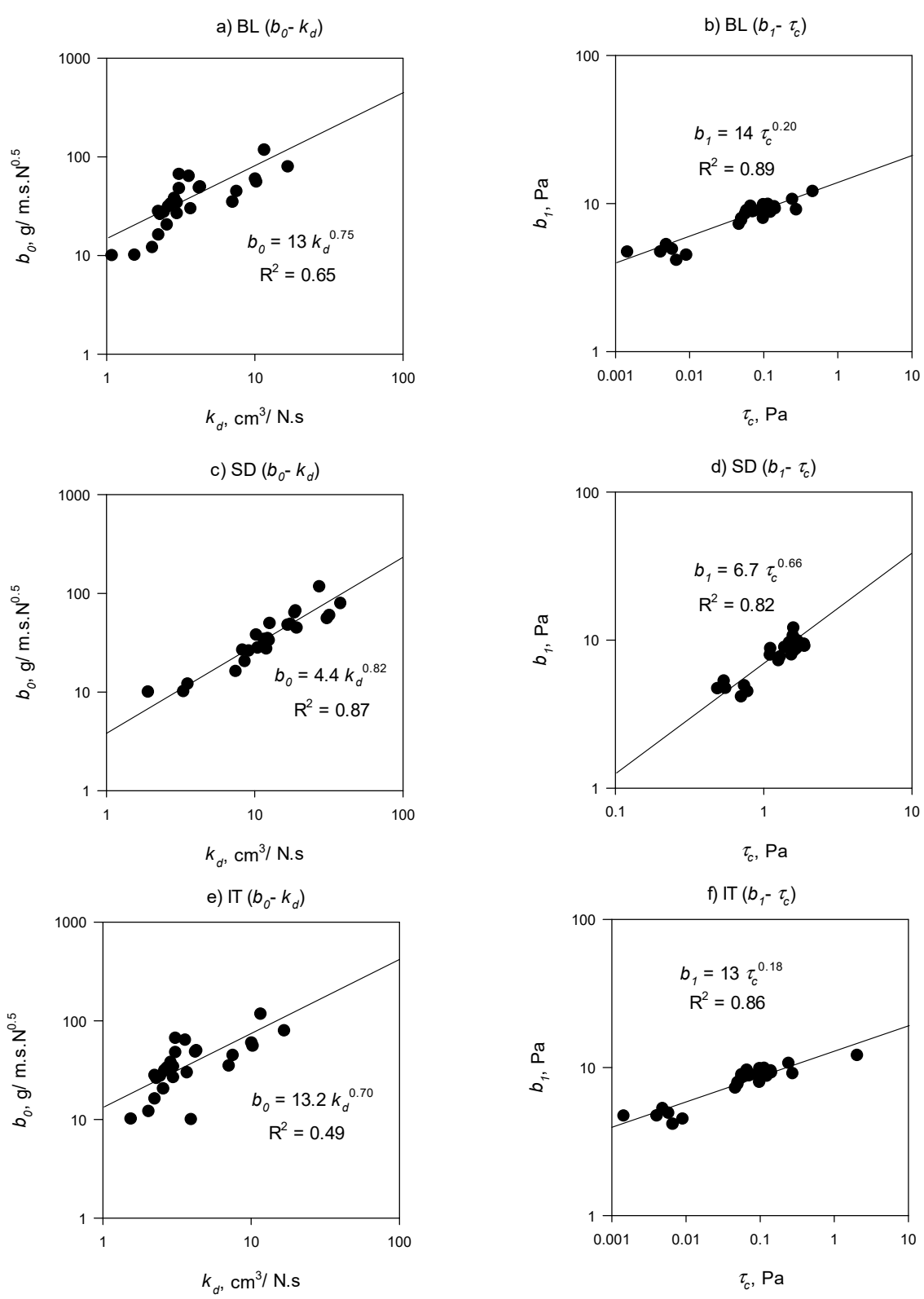

Figure 8. Relationship between Wilson model parameters and excess shear stress parameters for three different techniques: (a) BL $\left(b_{0}-k_{d}\right)$, (b) BL $\left(b_{1}-\tau_{c}\right)$, (c) $\operatorname{SD}\left(b_{0}-k_{d}\right)$, (d) $\mathrm{SD}\left(b_{1}-\tau_{c}\right)$, (e) IT $\left(b_{0}-k_{d}\right)$, and (f) IT $\left(b_{1}-\tau_{c}\right)$

\section{Summary and Conclusions}

Twenty- five tests were performed using "mini" JET device to investigate the influence of Lead pollution on cohesive soil erodibility and compared the analysis results of both excess shear stress (linear model) and Wilson model (nonlinear model). The results showed that the Lead pollution influence significantly on soil erodibility by accelerating the soil scouring as Lead concertation increased. The data of the "mini" JETs were analyzed with the linear model using three techniques (BL, SD, and IT solutions). The erodibility coefficient, $k_{d}$, increased when Lead concentration increased while the critical shear stress, $\tau_{c}$, decreased as Lead concertation increased for all three techniques. The variation in the bulk density had an important role on the soil erodibility and the 
Lead pollution had more influence on the soil of $1.4 \mathrm{~g} / \mathrm{cm}^{3}$ bulk density than the soil of $1.7 \mathrm{~g} / \mathrm{cm}^{3}$ bulk density. The Lead concertation had similar effect on Wilson model parameters $\left(b_{0}\right.$ and $\left.b_{I}\right)$ as excess shear stress parameters $\left(k_{d}\right.$ and $\left.\tau_{c}\right)$. The Wilson model explained the reason of increasing the erodibility due to increasing in the Lead concentration. The Wilson parameters $\left(b_{0}\right.$ and $\left.b_{l}\right)$ depend on the soil properties such as particle shape, density, orientation and soil cohesion. Therefore, the increasing in the concentration of Lead caused to the weakening of the cohesion forces and led to increased $b_{0}$ ( $b_{0}$ inversely proportional with the soil cohesion) and decreasing $b_{1}$. Similar to previous studies, inverse relationships of $k_{d}-\tau_{c}$ as well as to $b_{0}-b_{1}$ were observed which agreed with the previous research observations. The results of comparing excess shear stress model with Wilson model had showed that both $b_{0}$ and $b_{1}$ have similar behavior relative to Lead contamination to $k_{d}$ and $\tau_{c}$, respectively, but with different magnitude. The performance of SD technique and WL model were more consistent than $\mathrm{BL}$ and IT solution techniques. The mechanistic parameters $\left(b_{0}\right.$ and $\left.b_{1}\right)$ were resembled empirical parameters $\left(k_{d}\right.$ and $\left.\tau_{c}\right)$ for all three solution techniques, but with different magnitudes.

\section{References}

Al-Madhhachi, A. T., Hanson, G. J., Fox, G. A., Tyagi, A. K., \& Bulut, R. (2013a). Measuring soil erodibility using a laboratory “mini” JET. Trans. ASABE, 56(3), 901-910. http://dx.doi.org/10.1061/41173(414)244

Al-Madhhachi, A. T., Hanson, G. J., Fox, G. A., Tyagi, A. K., \& Bulut, R. (2013b). Deriving parameters of a fundamental detachment model for cohesive soils from flume and jet erosion tests. Trans. ASABE, 56(2), 489-504. http://dx.doi.org/10.13031/2013.42669

Al-Madhhachi, A. T., Fox, G. A., Hanson, G. J., Tyagi, A. K., \& Bulut, R. (2014a). Mechanistic detachment rate model to predict soil erodibility due to fluvial and seepage forces. J. Hydraul. Eng. - ASCE, 140(5). DOI:10.1061/(ASCE)HY.1943-7900.0000836

Al-Madhhachi, A. T., Fox, G. A., \& Hanson, G. J. (2014b). Quantifying the erodibility of streambanks and hillslopes due to surface and subsurface forces. T. ASABE, 57(4), 1057-1069. http://dx.doi.org/10.13031/trans.57.10416

Blaisdell, F. W., Clayton, L.A., \& Hebaus, C. G. (1981). Ultimate dimension of local scour. J. Hydraulics Division, ASCE, 107(HY3), 327-337

Briaud, J. L., Ting, C. K., Chen, H. C., Han, S. W., \& Kwak, K. W. (2001). Erosion function apparatus for scour rate predictions. J. Geotech. and Geoenviron. Eng. Division, ASCE, 127(2), 105-113.

Daly, E. R., Fox, G. A., Al-Madhhachi, A. T., and Miller, R. (2013). A scour depth approach for deriving erodibility parameters from Jet Erosion Tests. Trans. ASABE, 56(6), 1343-1351. http://dx.doi.org/10.13031/trans.56.10350

Daly, E. R., Fox, G. A., Al-Madhhachi, A. T., \& Storm, D. E. (2015). Variability of fluvial erodibility parameters for streambanks on a watershed scale. Geomorphology, 231(0), 281-291. http://dx.doi.org/10.1016/j.geomorph.2014.12.016

Einstein, H. A. (1950). The bed-load function for sediment transport in open channel flows. SCS Technical Bulletin No. 1026. Washington, DC: USDA.

Einstein, H. A., \& El-Samni, E. A. (1949). Hydrodynamic forces acting on a rough wall. Reviews Modern Physics, 21(3), 520-524.

Hanson, G. J. (1990a). Surface erodibility of earthen channels at high stresses. I: Open channels testing. T. ASAE, $33(1), 127-131$.

Hanson, G. J. (1990b). Surface erodibility of earthen channels at high stresses. II: Developing an in situ testing device. T. ASAE, 33(1), 132-137.

Hanson, G. J. (2001). Field and laboratory jet test testing method for determining cohesive material erodibility. Proc. Of Federal Interagency Sedimentation Conference, Reno, Nevada.

Hanson, G. J., \& Cook, K. (1997). Development of excess shear stress parameters for circular jet testing. ASAE Paper, 972227. St. Joseph, Mich: ASAE.

Hanson, G. J., \& Cook, K. (2004). Apparatus, test procedures, and analytical methods to measure soil erodibility in situ. Appl. Eng. Agr., 20(4), 455-462. http://dx.doi.org/10.13031/2013.16492

Hanson, G. J., \& Hunt, S. (2007). Lessons learned using laboratory JET method to measure soil erodibility of compacted soils. Appl. Eng. Agr., 23(3), 305-312. http://dx.doi.org/10.13031/2013.22686 
Hanson, G. J., \& Simon, A. (2001). Erodibility of cohesive streambeds in the loess area of the midwestern USA. Hydrological processes, 15(1), 23-38. http://dx.doi.org/10.1002/hyp.149

Partheniades, E. (1965). Erosion and deposition of cohesive soils. J. Hydraul. Div., ASCE, 91(1), 105-139.

Rahi, M. A., Al-Qaysi, M. R., \& Al Obaidy, A. M. (2014). Assessment of Trace Metal Distribution and Contamination in Surface Soils of Al-Waziriya, Baghdad. Engineering and Technology Journal, 32(A), 46, (1-9).

Regazzoni, P. L., Hanson, G. J., Wahl, T., Marot, D., and Courivaud, J. R. (2008). The influence of some engineering parameters on the erosion of soils. Fourth International Conference on Scour and Erosion (ICSE-4), Tokyo, Japan, November 5-7, 2008.

Sporting Arms and Ammunition Manufacturers Institute (SAAMI). (1996). Lead mobility at shooting ranges. EA Engineering, Science, and Technology, Inc.

Sahib, S. A. (2005). Evaluation of Lead Concentration in the Soil of Some Residential Areas of Baghdad City. M.Sc. Thesis, University of Technology.

Sang, J., Allen, P., Dunbar, J., \& Hanson, G. (2015). Development of semi-physically based model to predict erosion rate of kaolinite clay under different moisture. Can. Geotech. J., 52: 1-10, dx.doi.org/10.1139/cgj-2012-0274.

Simon, A., Thomas, R., \& Klimetz, L. (2010). Comparison and experiences with field techniques to measure critical shear stress and erodibility of cohesive deposits. Proc., 2nd Joint Federal Interagency Conference, Las Vegas, NV.

Stein, O. R., \& Nett, D. D. (1997). Impinging jet calibration of excess shear sediment detachment parameters. Trans. ASAE 40(6), 1573-1580. http://dx.doi.org/10.13031/2013.21421

Tyvoll, J. L., \& Cuber, M. M. (2002). The Transport and Adsorption of Lead in a Mattapex Series Soil in Wicomico County, Maryland. American Geophysical Union, Spring Meeting 2002

Wan, C. F., \& Fell, R. (2004). Laboratory tests on the rate of piping erosion of soils in embankment dams. Geotechnical Testing Journal, 27(3), 295-303. http://dx.doi.org/10.1520/GTJ11903

Wilson, B. N. (1993a). Development of a fundamental based detachment model. Transaction of ASAE, 36(4), $1105-1114$.

Wilson, B. N. (1993b). Evaluation of a fundamental based detachment model. Transaction of ASAE, 36(4), 1115-1122.

Wynn, T. M., \& Mostaghimi, S. (2006). The effects of vegetation and soil type on Streambank erosion, Southwestern Virginia, USA. Journal of the American Water Resources Association, 42, 69-82. http://dx.doi.org/10.1111/j.1752-1688.2006.tb03824

Wynn, T. M., Henderson, M., \& Vaughan, D. (2008). Changes in streambank erodibility and critical shear stress due to subaerial processes along a headwater stream, southwestern Virginia, USA. Geomorphology, 97(3), 260-273. http://dx.doi.org/10.1016/j.geomorph.2007.08.010

\section{Copyrights}

Copyright for this article is retained by the author(s), with first publication rights granted to the journal.

This is an open-access article distributed under the terms and conditions of the Creative Commons Attribution license (http://creativecommons.org/licenses/by/3.0/). 